\title{
LA ÉTICA EN EL HORIZONTE DE LA CRISIS DEL HUMANISMO \\ Jorge Issa*
}

RESUMEN: El sustrato antropológico del humanismo moderno manifiesta hoy su carácter aporético; el texto se concentra en el destino de la ética, intentando identificar las condiciones de su viabilidad en un horizonte transformado y proponiéndolas a manera de criterios de adecuación de la teoría ética actual.

PALABRAS ClAVE: humanismo, ética, racionalidad tecnológica, medio ambiente.
ABSTRACT: The anthropological bases of modern humanism are revealing their aporetic nature. This article focuses on the future of ethics attempting to find those conditions that could transform the current ethical theory in order to make it feasible in the future.

KEYwORDS: humanism, ethics, technological rationality, environment. 


\section{LA ÉTICA EN EL HORIZONTE DE LA CRISIS DEL HUMANISMO}

I

No he de abundar aquí en la ya excesivamente citada "crisis del humanismo". Consignaré únicamente que la frase no tiene un significado unívoco. Para unos, remite a una decadencia antropológica caracterizada por el entredicho en que el egoísmo y la razón instrumental han colocado la dignidad y la autonomía que constituyen -según se alega- la esencia del individuo. De acuerdo con este punto de vista, la técnica y el interés utilitario han convertido a los seres humanos en simples medios para fines que les son ajenos o que no comprenden. Las coordenadas de la decadencia se revelan en casi cualquier descripción de las sociedades desa- rrolladas: cosificación, masificación, competencia salvaje por los recursos, miseria y opresión. Cualquier novela cyberpunk de William Gibson o Bruce Sterling dibujaría inmejorablemente el cuadro de la "deshumanización": individuos cada vez más solitarios pululando en sociedades distópicas, acaso totalitarias, en un entorno de informatización ubicua y donde el cuerpo humano es objeto de toda clase intervenciones. El remedio consistiría en revivir los antiguos ideales humanistas; especialmente, en rescatar a la subjetividad humana del lugar cada vez más subordinado a que lo han arrojado los mecanismos impersonales de la objetividad científica y la productividad tecnológica, y volver a colocarlo en el puesto que le corres- 
ponde como centro y fin del universo -un puesto que le había conferido precisamente el humanismo renacentista.

Desde la perspectiva de Heidegger, sin embargo, la anterior definición de "crisis" -en gran medida deudora tanto del existencialismo como de la teoría crítica, y aun de cierta literatura del pasado siglo-, al concebir el problema como el de la restitución de la primacía del sujeto, es decir, como el de la reversión del desarraigo que la Modernidad le ha impuesto al hombre del lugar central que por derecho le corresponde, pierde de vista, en primer término, la esencial historicidad del modo de estar en el mundo de ese sujeto, cuyo retorno anhela para complacerse en la evidencia del sujeto ideal de la ciencia, así como la primordial diferencia entre el Ser y el ente, todo lo cual nos veda la verdad de nuestra posición en el mundo; pero olvida -en segundo lugary sobre todoque sólo por referencia a una trascendencia que lo afirma como señor del Ser, es decir-para ponerlo en palabras de Vattimo-, que "sólo enmascarándose en las apariencias 'imaginarias' del fundamento" puede el hombre arrogarse la posición de centro de la realidad. Lo anterior significaría que la imposibilidad -hoy para muchos evidente- de apelar a un principio

${ }^{1}$ Gianni Vattimo, El fin de la Modernidad, 1990, Barcelona, Gedisa, p. 34. último, a una verdad incondicionada, a un fundamento trascendente constituye el rostro genuino de la "crisis del humanismo".

Extraigo de lo anterior la consecuencia, relativamente modesta o débil, de que la antropología filosófica moderna, básicamente subjetivista y humanista, está siendo llamada seriamente a un ajuste de cuentas ante la necesidad-tradicionalmente sentida en el pensamiento occidental- de clarificar lo que el hombre es y de discernir, asimismo, cuál es el puesto que le corresponde en el cosmos. Pero añado una idea en la que ahora me interesa detenerme: que nos apremia, cuando menos en igual medida, la definición de lo que el hombre de nuestro días debe ser. Es éste un problema al que me referiré como el del destino que nuestro mundo presente reserva para la ética.

\section{II}

Mucho se ha dicho que, en los tiempos que corren, la ética pasa por serias dificultades. Existen quienes piensan que tal situación se debe principalmente a una acusada falta de dedicación moral por parte de los hombres de hoy. Tal diagnóstico admite cierto desorden moral, pero no lo achaca a un conjunto de preceptos putativamente equivocados, sino al hecho de que 
NOTAS

sólo una exigua minoría de personas ha decidido aplicarlos. Están también, por otro lado, aquellos que piensan que más bien enfrentamos un cuadro caracterizado por una patente expansión de la inmoralidad, tanto en el ámbito público como en el privado; un ascenso del nihilismo en la forma de narcisismo inmediatista y de indiferencia por el bienestar del mundo exterior (natural y social); en fin, un descrédito general de la ética. Para los primeros, la ética tradicional goza de buena salud, no así el mundo en que ella debería aplicarse. Para los segundos, en cambio, impera una crisis en ambas esferas, la cual exige, como primera reacción, una revisión crítica de la situación en que se encuentra la teoría ética, revisión que debería llevar a reencauzarla y a ponerla en condiciones de responder satisfactoriamente a los desafíos de la vida práctica contemporánea.

Me interesa abordar la situación de la ética en el mundo actual partiendo del examen de la postura que el filósofo español Ramón Queraltó expone en un artículo suyo, más o menos reciente. ${ }^{2}$ Frente a las dos opiniones antes enunciadas, la de Queraltó no está impregnada en absoluto de un sentimiento de crisis; de hecho, augura buenas perspectivas a la ética, a condición de que se renueve en

${ }^{2}$ Ramón Queraltó, "Mutaciones de la ética en la sociedad tecnológica contemporánea. Ética y felicidad humana", en Ludus Vitalis, vol. XVI, núm. 30, 2008, pp. 165-96. consonancia con las exigencias de la evolución del mundo, es decir, que se adecue a la mentalidad de individuos que, como ocurre en nuestro tiempo, pertenecen a sociedades dominadas por una racionalidad técnica.

Según él, el criterio constituyente de una racionalidad tecnológica es el de eficacia operativa, es decir, que los objetos, las acciones, etcétera, produzcan resultados inmediatos con los menores costos. Esto significa, desde ahora, que la dimensión tecnológica por excelencia es la dimensión pragmática y que, por tanto, ha quedado en el pasado la importancia central que revestía a la dimensión teórica. Como criterio fundacional de racionalidad, la pregunta esencialista (“¿qué es esto?”) se habría tornado obsoleta y habría dado paso a la pregunta pragmática ("¿para qué sirve esto?"). No es que se haya eclipsado por completo el interés (científico) por describir y explicar las estructuras de lo real; pero sí ha quedado subordinado a criterios de utilidad y aplicabilidad. Además, tal racionalidad, acicateada por la demanda social, pero, sobre todo por su propia naturaleza, tiende a expandirse, a abarcar toda la realidad y entenderla de acuerdo con sus patrones de eficacia, a crear respecto del mundo una visión more technologico. Finalmente, su estructura interna le impone expresarse en la transformación de la realidad y no 
de otra manera: es voluntad de poder que no podría, sin negar su modo de ser, posponer su aplicación al universo fáctico.

Queraltó admite que en las sociedades actuales todavía se negocia a veces con valores epistémicos, religiosos, morales, etcétera; que no todo se realiza, pues, según las pautas de la racionalidad tecnológica; pero insiste en que es referencia permanente de la racionalidad social, que el mundo gira ya alrededor de ella. Y tal preeminencia nos revela un rasgo central de la mentalidad individual y social contemporánea: una actitud generalmente pragmática, una arraigada convicción de que el criterio fundamental para valorar la acción es su eficacia en la producción de los resultados esperados.

A partir de esta premisa, se derivan algunos contrastes entre el hoy y el ayer que tocan el núcleo mismo de la ética. En la visión heredada, lo valioso era evidente en sí o bien se justificaba por su relación con principios últimos que no requerían ulterior fundamentación. En tanto, el valor de una acción, para un punto de vista pragmático, se manifiesta como utilidad, como capacidad para resolver problemas, para superar un obstáculo. El hombre de hoy no se someterá a lo ético por su valor intrínseco, sino porque haya constatado que sirve de alguna manera a su bienestar.
En segundo lugar, la estructura tradicional de la ética se expresaba en una jerarquía axiológica rígida: la posición de los valores solía ser invariable y dependía de su relación más o menos próxima con la esfera de los principios últimos e incondicionados. Pero esto no puede seguir vigente cuando lo que vale es solamente lo que sirve; así, que algo tenga valor o no, dependerá de su eficacia para resolver un problema. Y, dado que los problemas morales cambian en forma continua, sólo un sistema de valores dinámico y flexible tiene perspectivas de ser de utilidad. Por añadidura, en sociedades altamente complejas, pluralistas y multiculturales, por lo general son muchos los valores que inciden en las situaciones morales, de modo que no es posible pensar en soluciones eternas para las cosas humanas; por el contrario, un buen sistema será aquel que pueda maximizar en cada decisión la presencia de todos los valores involucrados.

Por último, "el cambio estructural de la ética en el actual momento histórico se puede representar por el paso de una ética en forma de pirámide a una ética en forma de retícula". ${ }^{3}$ Mientras que la estructura de las éticas tradicionales, con el propósito de evidenciar la jerarquía axiológica, ponía los principios fundamentales en la cúspide y descendía por estratos

${ }^{3}$ Op. cit., p. 179. 
NOTAS

hasta las normas más particulares, en una estructura a modo de red cada valor se presenta compartiendo líneas de interconexión con los otros y, en particular, sin depender de instancias "superiores" que le den un fundamento. Afirma Queraltó que "el grado de flexibilidad y de adaptación de los sistemas reticulares axiológicos a las diferentes situaciones de la vida humana sería mucho mayor que en la ética en forma de pirámide". ${ }^{4}$

En suma, de acuerdo con esta visión, no asistimos ni a una simple pérdida de valores ni a una disolución de la esfera de la moral. Antes bien, el fenómeno que a veces percibimos como un dislocamiento de la ética no es más que esta mutación profunda de su estructura interna. De hecho, los valores, lejos de desaparecer, se multiplican, y esto hace necesario un juicio ético más complejo en cada caso, pues ahora debemos atender a las condiciones pragmáticas de la realización de los valores, así como a su eficacia posible y a la maximización de su presencia en la acción moral. Pero tal complejidad no implica en modo alguno un declive de la ética, sino únicamente nuevos condicionamientos para su viabilidad.

La conclusión general de Queraltó es que, a los ojos del hombre contemporáneo, pragmático, indivi-

${ }^{4}$ Ibidem. dualista y siempre atento a reivindicar su autonomía, el valor ético sólo puede presentarse como dotado de interés y conveniencia para la vida humana. En pocas palabras: en una sociedad dominada por la racionalidad tecnológica, la ética será pragmática o no será. Si le resulta útil al individuo (para resolver conflictos y ayudarle a avanzar en su proyecto existencial), sobrevivirá: sus valores se presentarán como de interés social. De lo contrario, se condenará a desempeñar un papel decorativo, a no representar más que la posibilidad de una "conversación interesante".

La "nueva" ética pragmática, en contraste con el estilo de la filosofía tradicional, no desea excluir otras visiones: sólo espera servir al hombre y contribuir al logro de su felicidad. No obstante, siendo más flexible y adaptable que las éticas que invocan valores trascendentes o suprahistóricos, ayudará al ser humano a lograr un mejor ajuste existencial con la realidad. Al emerger del interior de su propia racionalidad - en vez de tratar de imponerse como instancia externa que lo pone en conflicto con sus propias inclinaciones-, le da siempre una poderosa razón para cultivar una existencia ética, a saber: que le sirve para su vida. 


\section{III}

Cabe preguntar, por supuesto, si una ética que tiende siempre a plegarse a los deseos de un universo de seres individualistas, virtualmente incapaces de cuestionar sus fines y sólo atentos a descubrir los medios más eficaces y económicos para alcanzarlos, indiferentes a las cuestiones que trascienden su pequeño ego y aún inconscientes de ellas, autoindulgentes y, por tanto, conformistas, y, en fin, recluidos casi siempre en un relativismo acomodaticio que inmuniza su proyecto de autorrealización frente a cualquier género de crítica; cabe preguntar - decía- si una ética que sólo busca complacer al individuo moldeado por la racionalidad técnica merece sobrevivir. Pero sospecho que, incluso, debe dudarse de que pueda llamarse propiamente ética.

Sin embargo, en este momento no quiero explorar más esta cuestión, ni otras que emergen de la revisión de la postura de Queraltó tales como: ¿es verdad que en el mundo actual no está más a discusión el predominio de la técnica, incluyendo implicaciones suyas como el tipo de racionalidad que ha impuesto en la sociedad? Y el sentimiento de crisis que a tantos aqueja en relación con la situación actual de la ética, ¿qué tanto se explica por el hecho de que las teorías heredadas no han sido capaces de ajustarse a criterios pragmáticos? $\mathrm{O}$ bien, ¿debe rescatarse a cualquier precio el ideal clásico de llevar una existencia ética, vale decir: incluso al precio de deformarlo a tal punto que se torne casi imposible de reconocer?

Aunque sin duda estas cuestiones ameritan mayor consideración, me concentraré, más bien, en rescatar el enfoque general que adopta Queraltó respecto del tema; un enfoque que se puede exponer en la forma de una importante pregunta: ¿cuáles son los desafíos que hoy enfrenta la ética a los que debería dar una respuesta satisfactoria para generar las condiciones de su propia viabilidad? Porque -sin prejuzgar acerca de si éstos son buenos o malos tiempos para la moral- una vez que se entiende que la ética se halla en un punto de inflexión, en un momento en que debe asumir definiciones importantes, se hace indispensable identificar los factores determinantes de la situación. Queraltó parte de esta pregunta y propone una respuesta que refleja un diagnóstico meramente parcial: si el destino de la ética ha de decidirse, hoy, de cara a las profundas mutaciones que acarreará para la ética el predominio social de una racionalidad técnica, es menester reconocer que la situación se configura también por la incidencia de otros factores cuya importancia no va a la zaga del que se ha estado exponiendo. A mi juicio hay otros dos, por lo menos, que requieren una atención similar y ellos 
NOTAS

son: ${ }^{5}$ la necesidad de mirar a través del cristal de la ética la muy mal avenida relación entre hombre y naturaleza, por una parte, y el declive del ideal ilustrado de hallar una única forma de vida válida para todos los hombres y que sea conforme con los dictados de la Razón.

Si bien no es ya tan inusitado el fenómeno de que una mala conducta ambiental concite la indignación moral de quienes la atestiguan, está claro que la reacción mayoritaria de la población mundial-indiferente en el mejor de los casos, pero en general complaciente o, inclusive, de plena aquiescencia- hacia los abusos que se cometen contra la naturaleza, cuenta todavía con el respaldo teórico de las diversas teorías éticas heredadas. En todas ellas se concede absoluta legitimidad a las acciones que abonan los intereses de los seres humanos y sólo se reconocen límites que tienen que ver con los derechos de sus semejantes. En su misma enunciación, las éticas tradicionales guardan un silencio ominoso acerca de los demás integrantes de la comunidad de la Tierra.

${ }^{5}$ Digo "por lo menos", pues aún es necesario evaluar en qué medida ha de considerarse como elementos estructurantes, es decir, necesarios (y no meramente contingentes o subordinados) en el trazado del panorama actual, a rasgos tan sintomáticamente característicos de la mentalidad del hombre contemporáneo tales como su acendrado y casi omnipresente individualismo (vid. Charles Taylor, La ética de la autenticidad, 1994, Barcelona, Paidós) o su muy acusada propensión al emotivismo ético (vid. Alasdair MacIntyre, Tras la virtud, 2001, Barcelona, Crítica).
Están hechas por hombres $\mathrm{y}$, ante todo, para los hombres: son, por ello, incapaces de modular, o siquiera moderar, el trato que los seres humanos dispensan a las otras entidades de la naturaleza. No hay duda de que la ética jamás se ha hecho cargo de la lección primordial que arroja la moderna ciencia de la ecología, la cual representa a la totalidad de las formas de vida del planeta como miembros iguales de una comunidad unitaria y no puede menos que enfatizar la necesaria interdependencia de todas las partes involucradas: plantas, animales, especies, ecosistemas e, inclusive, aire, suelos y aguas. Mientras la ética no asuma plenamente la obligación de normar el trato que da el hombre al universo natural (comenzando, quizá, por ensanchar el espacio de la considerabilidad moral, es decir, extendiendo sus fronteras para dar cabida a las entidades naturales no humanas; o bien, por lo menos, reservando en sus reflexiones un lugar primordial a nociones atinentes a una relación más sana con el medio ambiente tales como las de respeto, conservación, integridad, etcétera), seguirá siendo inviable como recurso para contender con los problemas morales del presente y del futuro.

Por otra parte, el giro que haya de dar la ética debe responder también a la decadencia probablemente irreversible del universalismo característico de la filosofía moderna, en particular, 
al derrumbe de "la concepción de una única forma de vida que, una vez introducida en el universo, podría fijarse eternamente, sin requerir alteración, porque era perfecta, satisfaciendo los intereses y deseos permanentes del hombre". ${ }^{6}$ No parece haber ya un freno posible a la culminación del proceso de secularización que la Modernidad ha llevado adelante en la forma de desmitificación de todo absoluto y de toda verdad última, incondicionada y universal. Tampoco cabe cerrar los ojos al hecho de que "el pluralismo es la ideología de nuestro tiempo [al punto de que] el pluralismo político define al Estado liberal democrático de nuestras sociedades". ${ }^{7}$ Es preciso, además, reconocer "la parcialidad de aquello que durante tantos siglos la filosofía europea había considerado como la esencia de la humanitas" a la luz de la afirmación del multiculturalismo, que penetra cada vez más en el mundo globalizado. En fin, que la moraleja que la ética ha de derivar de todas estas observaciones es que, en adelante, le estará vedado perseguir el espejismo de los primeros principios y que sólo podrá volver a aspirar a la universalidad por medio del diálogo en el contexto de una multiplicidad de

${ }^{6}$ Isaiah Berlin, Las raíces del Romanticismo, 2000, Madrid, Taurus, p. 55.

${ }^{7}$ J. M. Bermudo, "El pluralismo razonable de John Rawls", en Convivium, núm. 19, 2006, p. 117-44.

${ }^{8}$ Gianni Vattimo, Nichilismo ed emancipazione, 2003, Milano, Garzanti, p. 50. interpretaciones que en muchos casos se revelará, en última instancia, como verdaderamente irreductible.

Me parece que la centralidad de estos elementos en el panorama que presentan en general las sociedades de nuestro tiempo ( $\sin$ menoscabo -como antes se dijo- de la posibilidad de alargar pero seguramente no de abreviar la lista) nos permite hablar, inclusive, de que todos ellos conforman la base teórica en la que puede asentarse un conjunto de criterios de adecuación, al cual se ha de recurrir en la evaluación de toda ética futura. Diríase que, en principio, la ética sólo podrá subsistir en el mundo de hoy si es capaz de constituirse auténticamente como respuesta a varios y diversos desafíos: 1) a la necesaria consideración moral del interés por la conservación de la integridad de la naturaleza (si no es que a la franca apertura de un espacio a los "derechos" o los "intereses" que, con algún fundamento crítico, pudieren eventualmente atribuirse a las entidades naturales no humanas); 2) a la conciencia inevitable de que su "verdad" no podrá sino nacer del diálogo entre perspectivas diversas y expresarse sólo en la forma de consenso; $y, 3$ ) al dato insoslayable de que la racionalidad técnica que se ha impuesto en las sociedades modernas ha esculpido también, en el hombre de hoy, un perfil pragmático que amenaza 
NOTAS

con volver por completo prescindibles los valores morales que se acuñaron sin tener en cuenta estas nuevas realidades.

No hay duda de que no es viable limitarse sencillamente a insistir en un nuevo "rearme moral" de la humanidad, vale decir: en la sola importancia de "una adhesión más generalizada a una ética [que no tiene que ser nueva, sino a una que nos es ya] perfectamente conocida". ${ }^{10}$ Me parece que esto queda claro por el hecho de que los criterios de adecuación recién enunciados se derivan precisamente del análisis de las deficiencias que presentan las teorías éticas asentadas en los supuestos tradicionales: antropocéntricas todas ellas, asimismo rígidas y jerárquicas, fundadas en una putativa trascendencia o en principios "incondicionados", y en general, inconscientes del dominio avasallador y perverso de la razón instrumental en la mentalidad de sus destinatarios.

${ }^{9}$ Vid. W. K. Frankena, "Ethics and the Environment", en K.E. Goodpaster y K.M. Sayre (comps.), Ethics and Problems of the $21^{\text {st }}$ Century, 1979, Nostre Dame, University of Notre Dame Press, p. 3.

${ }^{10}$ John Passmore, Man's Responsibility for Nature, 1974, New York, Charles Scribner's Sons, p. 187.
En suma, necesitamos una nueva ética, pero no una que asuma que, para garantizar su sobrevivencia, simplemente se ha de acomodar a la racionalidad imperante, abdicando de este modo de su esencia crítica sin la cual no tiene razón de ser. Precisamos de una ética ambiental que nos rescate de la miopía homocéntrica y que oxigene la atmósfera, combatiendo nuestra contaminación mental. Necesitamos una ética de la responsabilidad que dé la cara al malestar y a la descomposición culturales y que, evitando efectivamente el esencialismo tradicional y rechazando también todo absoluto (incluido el tecnológico), procure la ampliación de nuestros horizontes deliberativos mediante una franca y bien dispuesta apertura al diálogo. Requerimos, en fin, una ética, no sólo para la búsqueda egoísta de nuestra felicidad, sino para la convivencia con el otro y para el enriquecimiento personal. 